\section{International Journal of Medical \\ Research and Review}

2020 Volume 8 Number 6 November-December
MEDRESEARCH

www.medresearch.in

\title{
Prevalence of diastolic dysfunction in Normotensive diabetics below 45 years of age
}

\author{
Sukhwani . $^{1 *}$, Jain M. ${ }^{2}$ \\ DOI: https://doi.org/10.17511/ijmrr.2020.i06.08 \\ 1* Nitesh Sukhwani, Associate Professor, Department of Medicine, Peoples College Of Paramedical Science \& Research Center, Bhopal, \\ Madhya Pradesh, India. \\ 2 Mohit Jain, Resident DNB Cardiology, 2nd year, Bansal Hospital, Bhopal, Madhya Pradesh, India.
}

Introduction: Dengue rarely affects the heart but clinical symptoms of cardiac involvement may range greatly from silent illness to severe myocarditis resulting in death. Clinical features are asymptomatic and most are transient among patients with DF/DHF. Material and methods: It was an observational study conducted at the Department of General Medicine, Peoples College of Medical Sciences and Research Centre, Bhopal. The total duration of the study was One and a half years from November 2016 to APR 2018. All normotensive diabetic patients less than 45 years of age presenting to the Department of General Medicine, Peoples College of Medical Sciences and Research Centre, Bhopal during one and half years from which data was collected using as per given proforma. Results: In the present study, It was found that significant Pearson's correlation between age of diabetics and diastolic changes in ECHO, and serum creatinine and diastolic changes in ECHO. The rest of the parameters like blood urea, blood pressure, RBS, FBS, PPBS, and duration of diabetes were not significantly correlated. Conclusion: It was concluded that in the present study, diabetes mellitus is itself a risk factor for developing diastolic dysfunction though its prevalence increases with increasing age, serum creatinine and there is no association found between duration of diabetes and diastolic dysfunction. So screening of every young normotensive diabetic for diastolic dysfunction should be done to prevent early cardiovascular disease.

Keywords: Diabetes, Normotensive, Diastolic dysfunction, ECHO

Corresponding Author

Nitesh Sukhwani, Associate Professor, Department of Medicine, Peoples College Of Paramedical Science \& Research Center, Bhopal, Madhya Pradesh, India. Email: drsukhwani@gmail.com
How to Cite this Article

To Browse

Sukhwani N, Jain M. Prevalence of diastolic dysfunction in Normotensive diabetics below 45 years of age. Int J Med Res Rev. 2020;8(6):424-428. Available From https://ijmrr.medresearch.in/index.php/ijmrr/article/ view/1239

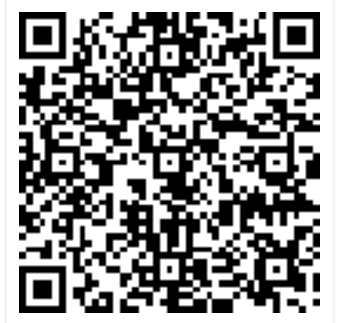

Manuscript Received 2020-12-24

Conflict of Interest No
Review Round 1 2020-12-26

Funding Nil

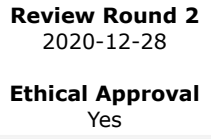

Review Round 3

Accepted 2020-12-31

Plagiarism X-checker $9 \%$

Note

(C) 2020 by Nitesh Sukhwani, Mohit Jain and Published by Siddharth Health Research and Social Welfare Society. This is an Open Access article licensed under a Creative Commons Attribution 4.0 International License 


\section{Introduction}

Epidemiological data indicate a greater risk of cardiovascular morbidity and mortality, particularly congestive heart failure, in diabetic subjects compared with nondiabetic subjects [1]. Clinical, epidemiological, and pathological studies attribute the increased occurrence of clinical congestive heart failure in diabetic subjects to diabetic cardiomyopathy, which could take the form of diastolic and/or systolic left ventricular dysfunction $[2,3]$. Left ventricular diastolic dysfunction (LVDD) may represent the first stage of diabetic cardiomyopathy [3], reinforcing the importance of early examination of diastolic ventricular function in individuals with diabetes.

Several hypotheses proposed for the advancement of diabetic cardiomyopathy including micro and macrovascular disease, autonomic dysfunction, metabolic abnormalities, interstitial fibrosis leading to myocardial hypertrophy, and diastolic dysfunction. The association between diastolic dysfunction and hyperglycemia is still a matter of debate. Diastolic dysfunction has been explained as a premature sign of diabetic heart disease evident before systolic damage. It is also responsible for early heart failure with maintained ejection fraction. The pathogenesis behind diastolic dysfunction remains unknown and numerous studies have been proposed but with uncertainty and still have been controversial.

There are a few studies that are conducted in India that show the coexistence of diastolic dysfunction and diabetes. But previous studies show an increased incidence of diastolic dysfunction in diabetics. It is approximately two times as common in men and five times common in women suffering from diabetes. So the purpose of the present study is to detect the exact frequency of diastolic dysfunction in asymptomatic young diabetics and to use an echocardiogram as an early detector of diastolic dysfunction. So preventive and interventional measures can be targeted to prevent both diastolic dysfunction and early stages of heart failure.

\section{Material and Methods}

Study Design: Observational study

Duration of Study: One and a half years. (November 2016 to April 2018)
Place of Study: The study was conducted at the Department of General Medicine, Peoples College of Medical Sciences and Research Centre, Bhopal.

Source of Data: All the cases with Diabetes below 45 years of age attending OPD/IPD in the Department of General Medicine, PCMS, and RC Bhopal during the above said period of one and half years.

Sample Size: All cases with Diabetes below 45 years of age presenting to People's Hospital during one and half years from which data was collected using as per given proforma.

\section{Inclusion Criteria}

Diabetes patients which include

- Newly diagnosed DM with normal sinus rhythm.

- $\mathrm{K} / \mathrm{C} / \mathrm{O}$ diabetes mellitus with normal sinus rhythm.

- AGE- <45Years

\section{Exclusion Criteria}

- Patients with known Coronary artery disease

- Patients with Chronic obstructive pulmonary disorder, severe anemia.

- Patients taking medications that can cause cardiac dysfunction like lithium, oral contraceptive pills.

- Patient with arrhythmia like AF.

\section{Data Collection Procedure}

Patients who had given written informed consent been are enrolled after reading the consent in the local language. All patients of diabetes coming to OPD/IPD were investigated for routine blood investigations like complete hemogram, renal function tests, liver function test, chest radiography, and ultrasonogram of the abdomen. Electrocardiography and Echocardiography for cardiac involvement were done by an ECG machine and $2 \mathrm{~d}$ and Color Doppler echo machine (siemens acuson $\times 300$ ).

\section{Diagnosis of diabetes mellitus}

"Fasting blood sugar (FBS) $\geq 126 \mathrm{mg} / \mathrm{dL}$ (7.0 $\mathrm{mmol} / \mathrm{L}$ ) or 2 -h blood sugar $\geq 200 \mathrm{mg} / \mathrm{dL}$ (11.1 $\mathrm{mmol} / \mathrm{L}$ ) during an oral glucose tolerance test (OGTT) or HbA1c $\geq 6.5 \%$ or Classic diabetes symptoms + random plasma glucose $\geq 200 \mathrm{mg} / \mathrm{dL}$ (11.1 mmol/L)" [4]. 
Data Management and Statistical analysis: Microsoft Excel $® 2010$ was used for the compilation of data while MedCal $®$ (version 19.0.5) software was used for statistical treatment. Full patient information was included and maintained during the entire study period. The supervisor monitored the completeness and quality of the gathered data periodically.

\section{Results}

Table-1: Distribution of the patients according to age.

\begin{tabular}{|l|l|l|}
\hline \multicolumn{1}{|c|}{ Age group in years } & Frequency & \multicolumn{1}{c|}{ Percentage (\%) } \\
\hline $0-15$ & 18 & 36.0 \\
\hline $15-30$ & 14 & 28.0 \\
\hline $30-45$ & 18 & 36.0 \\
\hline Total & 50 & 100.0 \\
\hline
\end{tabular}

In the present study, out of a total of 50 subjects 17 (34\%) were females and $33(66 \%)$ were males. 18 (34\%) subjects were in the $0-15$ years age group, $14(28 \%)$ subjects were in the $15-30$ years age group and 18 (34\%) subjects were in the $15-45$ years age group.
Table-2: Distribution of the patients according to ECHO findings.

\begin{tabular}{|l|l|l|}
\hline \multicolumn{1}{|c|}{ ECHO } & Frequency & Percentage (\%) \\
\hline Grade 1 Diastolic Dysfunction & 26 & 52.0 \\
\hline Grade 2 Diastolic Dysfunction & 4 & 8.0 \\
\hline Normal function & 20 & 40.0 \\
\hline Total & 50 & 100.0 \\
\hline
\end{tabular}

In the present study, out of a total of 50 patients, $26(52 \%)$ had grade 1 diastolic dysfunction and 4 $(8 \%)$ had grade 2 diastolic dysfunction.

Table-3: Mean and standard deviation of all parameters.

\begin{tabular}{|l|l|l|}
\hline \multicolumn{1}{|c|}{ Parameter } & \multicolumn{1}{c|}{ Mean } & \multicolumn{1}{c|}{ Std. Deviation } \\
\hline FBS & 197.4160 & 60.05881 \\
\hline PPBS & 286.0912 & 88.66274 \\
\hline RBS & 278.3400 & 75.72092 \\
\hline Urea & 24.6752 & 8.68515 \\
\hline Serum Creatinine & .6596 & .26262 \\
\hline Systolic BP & 116.0000 & 9.03508 \\
\hline Diastolic BP & 75.0000 & 6.14452 \\
\hline
\end{tabular}

Mean and standard deviation of different parameters like FBS, PPBS, RBS, Urea, Serum creatinine, Systolic BP, and Diastolic BP.

Table 4: Correlation of ECHO with different parameters

\begin{tabular}{|l|l|l|l|l|l|l|l|l|l|l|}
\hline & \multicolumn{1}{|c|}{ Association } & Age & Urea & Serum Creatinine & Diastolic BP & Systolic BP & RBS & FBS & PPBS & \multicolumn{1}{c|}{ Duration } \\
\hline \multirow{2}{*}{ ECHO } & Pearson Correlation & .296 & .249 & .336 & .134 & .228 & .083 & .249 & .084 & 5.507 \\
\cline { 2 - 10 } & P value/ Sig. (2-tailed) & $.037 *$ & .081 & $.017 *$ & .353 & .111 & .567 & .081 & .563 & .239 \\
\hline
\end{tabular}

In the present study, it was found significant Pearson's correlation between the age of diabetics and diastolic changes in $\mathrm{ECHO}$, and serum creatinine and diastolic changes in ECHO. The rest of the parameters like blood urea, blood pressure, RBS, FBS, PPBS, and duration of diabetes were not significantly correlated.

\section{Discussion}

This observational study was based on echocardiographic findings to detect the prevalence of diastolic dysfunction in 50 diabetic patients under 45 yrs of age with normal blood pressure and with no preceding history of cardiac disease. In the present study, various parameters of age, sex, FBS, PPBS, RBS, Systolic, and diastolic blood pressure, and Serum creatinine were taken. Out of 50 patients, 26 patients had grade 1 diastolic dysfunction and 4 patients had grade two diastolic function.
In the present study, it was found a positive correlation between age of the subjects and diastolic dysfunction with a p-value of 0.037 which is significant and suggests an association of diastolic dysfunction with increasing age as corroborated by Ashour Kamil [5] in his study "early detection of diastolic dysfunction in diabetics patients singlecenter cross-sectional study" which shows diastolic dysfunction is significantly higher in patients with age $>45$ years as compared to age<45years. ( $p$ value<0.05). Diastolic dysfunction is compared with FBS levels; it shows that with a p-value of 0.081 which shows the insignificant association of raised FBS and diastolic dysfunction. In a study conducted by Assi Milwidsky et al [6]. LVDD was diagnosed in $19 \%$ of subjects and it was more prevalent among patients with IFG and DM than in euglycemic individuals, concluding that IFG is independently associated with a significant increase in the likelihood for the presence of LVDD in middle-aged adults. 
Diastolic dysfunction was compared with PPBS level, in the present study, subjects had no diastolic dysfunction. With a p-value of 0.554 which is insignificant suggest that there is no important variation when compare with PPBS level, but the study "Prevalence of asymptomatic LV diastolic dysfunction in type 2 diabetic patients and healthy controls" by G Suresh et al [7] suggested that diastolic dysfunction is more prevalent in patients PPBS level $>199 \mathrm{mg} / \mathrm{dl}$. In the present study, there was no significant correlation between RBS and diastolic dysfunction with a $\mathrm{p}$-value of 0.554 there, but Virendra $C$ Patil et al concluded that diastolic dysfunction is associated with high $\mathrm{HbA1C}$ and sugars level [8].

In the present study, there was a significant correlation between serum creatinine and diastolic dysfunction with a p-value of 0.014 which is significant suggesting an association between raised serum creatinine and diastolic dysfunction as denoted by Jennifer E Liu MD et al [9] in their study "association of albuminuria with systolic and diastolic dysfunction in type two diabetes" suggest that microalbuminuria and nephropathy are independent risk factors for the development of diastolic dysfunction in diabetics ( $p$-value 0.001 ).

In the present study, there was no significant correlation between systolic and diastolic blood pressure and diastolic dysfunction but a study conducted by Fellcio JS et al [10] on hyperglycemia and nocturnal systolic blood pressure are associated with left ventricular hypertrophy and diastolic dysfunction in diabetic patients. Study shows that higher NSBP levels are associated with a high incidence of LVH and diastolic dysfunction in patients of type 2 DM ( $p$ value $<0.5$ ). Another study conducted by Casare Russo et al [11], in their study suggests that high blood pressure diabetes are independent risk factors for LV diastolic dysfunction $\mathrm{p}$-value $<0.05$.

In the present study, there was no significant correlation between duration of diabetes and diastolic dysfunction with a $\mathrm{p}$-value of 0.239 which is insignificant. However in a study conducted by Aaron M MD et al [12], there was a significant association between the $\mathrm{E} / \mathrm{e}^{\prime}$ ratio and the time from diabetes diagnosis to echocardiogram using simple linear regression; for every 1 year after the onset of diabetes, the $E / \mathrm{e}^{\prime}$ increased by 0.23 ( $\mathrm{p}$ value $=0.007$ ) after adjustment for age, gender, body mass index, prior coronary disease, prior hypertension and ejection fraction,
Moreover, duration of diabetes $\geq 4$ years was independently associated with LV diastolic dysfunction $\left(E / e^{\prime}>15\right)$ in multivariable logistic regression modeling after adjustment for age, gender, body mass index, prior coronary disease, prior hypertension and ejection fraction ( $p$ value $=0.007$ ).

\section{Conclusion}

It was concluded that in the present study, diabetes mellitus is itself a risk factor for developing diastolic dysfunction though its prevalence increases with increasing age, serum creatinine and there is no association found between duration of diabetes and diastolic dysfunction. So screening of every young normotensive diabetic for diastolic dysfunction should be done to prevent early cardiovascular disease.

\section{What does the study add to the existing knowledge?}

A positive correlation is found between diastolic dysfunction and normotensive diabetics below 45 years of age but there is no significant association between duration of diabetes and diastolic dysfunction.

\section{Author's contribution}

Dr. Nitesh Sukhwani: Concept, study design

Dr. Mohit Jain: Manuscript writing

\section{Reference}

01. Kannel WB, Hjortland M, Castelli WP. Role of diabetes in congestive heart failure- the Framingham Study. Am J Cardiol. 1974;34(1)29-34.

doi: $\quad 10.1016 / 0002-9149(74) 90089-7 \quad$ [Crossref]

02. Zarich SW, Nesto RW. Diabetic cardiomyopathy. Am Heart J. 1989;118(5-1)1000-1012.

doi: $\quad 10.1016 / 0002-8703(89) 90236-6 \quad$ [Crossref]

03. Raev DC. Which left ventricular function is impaired earlier in the evolution of diabetic cardiomyopathy?- An echocardiographic study of young type I diabetic patients. Diabetes Care. $1994 ; 17(7) 633-639$.

doi: $10.2337 /$ diacare.17.7.633 [Crossref] 
04. American Diabetes Association. Classification and diagnosis of diabetes. Diabetes Care. 2017;40(1)S11-S24.

doi: $10.2337 /$ dc17-S005 [Crossref]

05. Ashour K. Early Detection of Diastolic Dysfunction in Diabetic Patients (Single Center Cross Sectional Study). J Heart Cardiovasc Res. 2018;2(1-3).

[Crossref]

06. Milwidsky A, Maor E, Kivity S, Berkovitch A, Zekry SB, Tenenbaum A, et al. Impaired fasting glucose and left ventricular diastolic dysfunction in middle-age adults- a retrospective crosssectional analysis of 2971 subjects. Cardiovasc Diabetol. 2015;14(1)119.

doi: 10.1186/s12933-015-0282-4 [Crossref]

07. Suresh G, Alva R, Prakash P, Saya R. Prevalence of asymptomatic left ventricular diastolic dysfunction in type 2 diabetic patients and healthy controls- a comparative study. Arch Med Health Sci. 2017;5(1)30-33.

doi: 10.4103/amhs.amhs_92_16 [Crossref]

08. Patil VC, Patil HV, Shah KB, Vasani JD, Shetty P. Diastolic dysfunction in asymptomatic type 2 diabetes mellitus with normal systolic function. J Cardiovasc Dis Res. 2011;2(4)213-222.

doi: $10.4103 / 0975-3583.89805$ [Crossref]
09. Liu JE, Robbins DC, Palmieri V, Bella JN, Roman MJ, Fabsitz R, et al. Association of albuminuria with systolic and diastolic left ventricular dysfunction in type 2 diabetes- The Strong Heart Study. J Am Coll Cardiol. 2003;41(11)2022-2028.

doi: $10.1016 /$ s0735-1097(03)00403-0 [Crossref]

10. Felício JS, Pacheco JT, Ferreira SR, Plavnik F, Moisés VA, Kohlmann $O$, et al. Hyperglycemia and nocturnal systolic blood pressure are associated with left ventricular hypertrophy and diastolic dysfunction in hypertensive diabetic patients. Cardiovasc Diabetol. 2006;5(1)19. doi: $10.1186 / 1475-2840-5-19$ [Crossref]

11. Russo C, Jin Z, Homma S, Rundek T, Elkind MS, Sacco RL, et al. Effect of diabetes and hypertension on left ventricular diastolic function in a high-risk population without evidence of heart disease. Eur J Heart Fail. 2010;12(5)454-461.

doi: 10.1093/eurjhf/hfq022 [Crossref]

12. From AM, Scott CG, Chen $\mathrm{HH}$. Changes in diastolic dysfunction in diabetes mellitus over time. Am J Cardiol. 2009;103(10)1463-1466.

doi: 10.1016/j.amjcard.2009.01.358 [Crossref] 